J. Lake Sci. (湖泊科学), 2022, 34(1): 174-183

DOI 10. 18307/2022. 0105

(c) 2022 by Journal of Lake Sciences

\title{
食物与桡足类营养级对亚热带分层水库浮游动物群落结构的影响
}

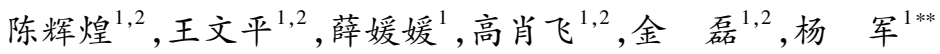 \\ ( 1 : 中国科学院城市环境研究所, 城市环境与健康重点实验室, 福建省流域生态重点实验室, 水生态健康研究组, 厦门 \\ 361021) \\ (2: 中国科学院大学, 北京 100049)
}

\begin{abstract}
摘 要: 于 2014 年 10-12 月,采集厦门溪东水库浮游动物、浮游植物、浮游细菌与悬浮物样品, 分析浮游动物群落与食 物质量和食物浓度的关系, 探讨桡足类营养级变化对浮游动物的影响. 结果表明, 空间上后生浮游动物群落结构在水库 不同水层间的差异不显著; 时间上桡足类在水华期和非水华期的差异不显著,枝角类和轮虫在水华期和非水华期的差异 显著. 桡足类群落组成受食物质量的影响较大, 枝角类群落组成受食物浓度的影响较显著, 轮虫群落组成受食物质量和 食物浓度的共同影响. 进一步分析表明,食物质量和食物浓度与水温显著相关,枝角类生物量受食物浓度的影响, 桡足类 生物量与轮虫生物量呈显著相关. 为了探究桡足类与食物质量的关系, 我们以优势种舌状叶镖水蚤 (Phyllodiaptomus tunguidus) 为对象分析化学计量特征, 发现舌状叶镖水虫体内的磷含量与水柱总磷平均浓度和水温呈显著正相关, 其营养级 变化范围为 $1.28 \sim 2.84$, 且营养级随着水温下降而显著增加. 非水华期的食物磷含量增加可能是舌状叶镖水虫丰度升高 的原因之一, 降温和种群繁殖的共同影响导致非水华期舌状叶镖水蚤体内磷含量逐渐下降, 营养级增加. 研究结果可为 揭示浮游动物在富营养化内陆水体中的群落演变过程机制提供基础数据.
\end{abstract}

关键词: 蓝藻水华;浮游细菌;悬浮物;微食物网;化学计量;溪东水库

\section{Effect of food and copepod trophic level on zooplankton community structure in a subtrop- ical stratified reservoir*}

\author{
Chen Huihuang ${ }^{1,2}$, Wang Wenping ${ }^{1,2}$, Xue Yuanyuan ${ }^{1}$, Gao Xiaofei ${ }^{1,2}$, Jin Lei $^{1,2}$ \& Yang Jun ${ }^{1 * *}$ \\ (1: Aquatic EcoHealth Group, Fujian Key Laboratory of Watershed Ecology, Key Laboratory of Urban Environment and \\ Health, Institute of Urban Environment, Chinese Academy of Sciences, Xiamen 361021, P.R. China) \\ (2: University of Chinese Academy of Sciences, Beijing 100049, P.R.China)
}

\begin{abstract}
To analyze the relationship between zooplankton community structure and food quality or food concentration, and to explore the effect of copepod trophic level change on zooplankton community, the suspended matter, free-living bacteria, phytoplankton and zooplankton samples were collected in Xidong Reservoir in Xiamen from October to December of 2014. The results showed that the community structure of zooplankton did not exhibit significant difference along the water column. The community structure of copepod between the cyanobacterial bloom stage and the non-bloom stages was similar, whereas the cladocera and rotifera during cyanobacterial bloom and non-bloom stages were significantly different. Further, our results showed that the effect of food quality on copepod was significant, the effect of food concentration on cladocera was significant, while the effect of food quality and food concentration on rotifera was significant. Food quality and food concentration were significantly correlated with water temperature, copepod biomass was significantly related with rotifera biomass, cladocera biomass was significantly correlated with food concentration. In order to explore the relationship between copepod and food quality, the dominant species (Phyllodiaptomus tunguidus) was selected to analyze the stoichiometric characteristics. The results showed that the phosphorus content of $P$. tunguidus body was significantly and positively correlated with the average concentration of total phosphorus in water column and water tem-
\end{abstract}

* 2021-01-31 收稿;2021-08-30 收修改稿.

国家自然科学基金项目 (91851104)、福建省自然科学基金重点项目 (2019J02016) 和中国科学院野外站联盟项目 (KFJ-SW-YW036) 联合资助.

** 通信作者;E-mail:jyang@iue.ac.cn. 
perature. The trophic level of $P$. tunguidus varied from 1.28 to 2.84 during the investigation period, and the trophic level increased significantly with the decrease of water temperature. Our results showed that the high quality of food in non-bloom stage was one of the reasons for the high abundance of $P$. tunguidus. In non-bloom stage, the joint effects of water temperature decrease and population reproduction led to decrease in the phosphorus content of $P$. tunguidus, and increase in the trophic level. These results provide the fundamental data for revealing the dynamic processes and mechanism of zooplankton community in eutrophic inland waters.

Keywords: Cyanobacterial bloom; bacterioplankton; suspended matter; microbial food web; stoichiometry; Xidong Reservoir

目前, 我国是世界上水库数量最多的国家, 随着城镇化进程的加快和地下水的短缺, 越来越多的水库被 选为城镇供水水源地 ${ }^{[1-3]}$. 作为饮用水水源地的水库, 管理者对水库采取鱼类养殖限制或禁止措施, 加之水 库水体较深、水位波动较大, 导致深水水库缺少底栖动物、挺水和沉水植物, 因此, 浮游生物成为水库生态系 统的主要组成部分.

淡水浮游生物包括细菌、浮游植物 (藻类) 、微型动物等, 是生态和进化地位都十分重要、独特、多样的类 群. 它们既是水生态系统的生产者、也是消费者和分解者, 在物质循环、污染物降解和水体自净等方面发挥 基础和关键作用 ${ }^{[2-3]}$. 后生浮游动物一方面以县浮物为食, 另一方面又是鱼类和其他高等水生动物的天然饵 料 ${ }^{[4]}$. 浮游动物群落组成和种群生长受多种因素影响, 除了鱼类捕食压力外 ${ }^{[5]}$, 还容易受食物的影响 ${ }^{[6-8]}$. 食 物的种类 ${ }^{[9]}$ 质量 ${ }^{[10]}$ 和大小 ${ }^{[11-12]}$ 对浮游动物种群动态具有一定的影响, 浮游生物生态模型 ( plankton ecology group model) 中强调了食物质量对后生浮游动物的重要性. 食物质量包括了化学计量组成、生物化学成分和 食物的形态特征 ${ }^{[6]}$. 温度也是影响浮游动物选择性摄食食物的主要原因, 研究发现浮游动物在高温条件下 偏好摄食碳含量高的自养生物, 低温条件下偏好摄食异养生物 ${ }^{[13]}$. 此外, 水位波动 ${ }^{[14]}$ 、气象和水文的组合干 扰 $^{[15]}$ 影响浮游植物的生物量和群落组成, 浮游植物会显著影响到浮游动物群落结构 ${ }^{[16]}$. 因此, 后生浮游动 物群落结构与动态受多重因素的影响, 本研究拟探讨食物质量和食物浓度对浮游动物的影响.

溪东水库是厦门市重要的供水水库,2014 年 10 月水库曾发生蓝藻(微囊藻) 水华. 水库蓝藻水华促进 底层水体厌氧氨氧化菌丰度的显著增加, 随着蓝藻水华的消亡, 水库的水质逐渐恢复 ${ }^{[17]}$. 蓝藻水华期间自 由生浮游细菌的抗生素抗性基因比非水华期间的丰度低 ${ }^{[18]}$. 蓝藻水华也显著改变了真核浮游微生物的群 落组成 ${ }^{[19]}$. 水华期和水华消退后的水库后生浮游动物群落组成在时空上是否发生变化? 食物质量 (水体碳 磷比、氮磷比) 如何影响到浮游动物? 食物浓度 (细菌丰度、浮游植物生物量) 如何影响浮游动物? 针对这些 尚未充分解答的问题, 本文以溪东水库为例, 分水层采集水华期至水华消退后的浮游生物样品, 分析后生浮 游动物群落结构与环境因子的关系. 旨在阐明食物质量和食物浓度对浮游动物群落变化的贡献, 揭示环境 因子对浮游动物化学计量 (磷) 特征的影响.

\section{1 材料与方法}

\section{1 样品采集}

溪东水库位于福建省厦门市同安区, 厦门的单位面积水库数量在福建省各市中最高, 但人均蓄水量最 低 ${ }^{[20]}$. 溪东水库坝址以上控制流域面积为 $23.4 \mathrm{~km}^{2}$, 库容 $0.14 \times 10^{8} \mathrm{~m}^{3}$, 平均水深 $23 \mathrm{~m}$, 多年平均气温 $20.7^{\circ} \mathrm{C}$, 多年平均降雨量为 $1335.8 \mathrm{~mm}$, 多年日照时数 $1914 \mathrm{~h}$. 根据 2014 年厦门市气候公报, 2014 年同安区 年平均气温偏高, 为 $22.2^{\circ} \mathrm{C}$; 年降水量偏少, 为 $1308.9 \mathrm{~mm}$; 日照时数偏少, 为 $1620 \mathrm{~h}$. 于 2014 年 $10-12$ 月对 溪东水库大坝前水体 $\left(24^{\circ} 49^{\prime} \mathrm{N}, 118^{\circ} 10^{\prime} \mathrm{E}\right)$ 进行采样, 采集表层 $(0.5 \mathrm{~m})$ 、氧跃层或温跃层 $(12 \sim 20 \mathrm{~m})$ 和底层 $(25 \mathrm{~m}$ ) 水样,共采 6 次 (采样日 297、304、325、332、346 和 363 对应具体日期分别为 2014 年的 10 月 24 日、10 月 31 日、11月 21 日、11 月 28 日、12 月 12 日和 12 月 29 日), 采样期间的理化因子变化趋势参见文献 [18-19].

\section{2 现场理化测定}

沿着水库水体垂直剖面,用多参数水质分析仪 (美国 HACH, Hydrolab DS5) 测定水体表层至底层每 0.5 $\mathrm{m}$ 的水温、 $\mathrm{pH}$ 、溶解氧 ( DO) 浓度、浊度、叶绿素 $a($ Chl.$a)$ 浓度、电导率、氧化还原电位 (ORP), 用塞氏透明度 盘监测水体透明度 ${ }^{[21]}$. 


\section{3 营养盐及叶绿素 $a$ 浓度分析}

用 $5 \mathrm{~L}$ 采水器分别采集表层 $(0.5 \mathrm{~m})$ 、氧跃层 $(12 \sim 20 \mathrm{~m})$ 和底层 $(25 \mathrm{~m})$ 水样, 每层收集 $1 \mathrm{~L}$ 水样, 带回实 验室分析总碳、总有机碳、总氮、亚硝酸盐 $\left(\mathrm{NO}_{2}^{-}-\mathrm{N}\right)$ 、硝酸盐 $\left(\mathrm{NO}_{3}^{-}-\mathrm{N}\right)$ 、氨氮 $\left(\mathrm{NH}_{3}-\mathrm{N}\right)$ 、总磷和磷酸盐 $\left(\mathrm{PO}_{4}^{3-}-\mathrm{P}\right)$ 浓度 ${ }^{[21-22]}$. 用 PHYTO-PAM 浮游植物苂光仪 (德国 Heinz Walz GmbH) 直接测定水样的蓝藻、绿藻和杂色藻以 及浮游植物总 Chl. $a$ 浓度 ${ }^{[17]}$.

\section{4 悬浮物}

悬浮物样品用 $5 \mathrm{~L}$ 采水器采集表层水样 $\left(0.5 \mathrm{~m}\right.$ ), 过滤到预灼烧 (经 $500^{\circ} \mathrm{C}, 4 \mathrm{~h}$ 的灼烧) 的 Whatman $\mathrm{GF} /$ $\mathrm{F}$ 滤膜上, 收集 3 份碳稳定同位素样品, 3 份氮稳定同位素样品, 在 $50^{\circ} \mathrm{C}$ 下烘干 $48 \mathrm{~h}$ 至恒重. 碳稳定同位素 样品用 $12 \mathrm{~mol} / \mathrm{L}$ 浓盐酸在干燥器熏蒸 $4 \mathrm{~h}$ 处理, 之后在 $50^{\circ} \mathrm{C}$ 烘箱再次干燥 $4 \mathrm{~h}^{[23]}$. 最后所有悬浮物样品均 保存在真空干燥器中.

\section{5 自由生浮游细菌}

自由生浮游细菌 $(0.22 \sim 3 \mu \mathrm{m})$ 样品用 $5 \mathrm{~L}$ 采水器采集表层、氧跃层和底层水样, 样品带回实验室. 水样 先经 $3 \mu \mathrm{m}$ 孔径滤膜过滤, 再经 $0.2 \mu \mathrm{m}$ 滤膜(美国 Millipore) 过滤. 滤膜置于 $-80^{\circ} \mathrm{C}$ 冰箱, 直至 DNA 提取 ${ }^{[21]}$. 浮游细菌 DNA 提取使用 FastDNA SPIN Kit (美国 MP Biomedicals) 方法. 浮游细菌的 16S rRNA 基因拷贝数 测定采用 SYBR-Green 苂光探针法和 Lightcyler480 仪器 (瑞士 Roche) 进行定量 PCR 分析. 主要步骤为 ${ }^{[21]}$ : 1) 制作标准曲线; 2 ) 每个样品包括 3 个平行样, 并设置阴性及阳性对照. $16 \mathrm{~S}$ rRNA 基因 PCR 引物为 $341 \mathrm{~F}$ : (5'-CCTACGGGNGGCWGCAG-3') 和 515R (5'-ATTCCGCGGCTGGCA-3'), 每个 PCR 反应均采用 $20 \mu \mathrm{L}$ 体系, 其组成包括: $10 \mu \mathrm{L}$ SYBR Premix Ex Taq ${ }^{\mathrm{TM}}$ (日本 Takara Bio Inc.) 、2 $\mu \mathrm{L}$ 模板 DNA、各引物浓度都为 0.25 $\mu \mathrm{mol}$ 、最后用 RNase-free 水补齐到 $20 \mu \mathrm{L}$. 按照说明书设定扩增反应程序为: $95^{\circ} \mathrm{C}$ 预变性 $3 \mathrm{~min}$; 40 个循环: $95^{\circ} \mathrm{C}$ 变性 $15 \mathrm{~s}, 56^{\circ} \mathrm{C}$ 退火 $34 \mathrm{~s}^{[21]}$. 本研究中, $\mathrm{PCR}$ 扩增效率为 $90 \% \sim 110 \%$.

\section{6 浮游植物}

浮游植物定量样品用 $5 \mathrm{~L}$ 采水器采集表层、氧跃层和底层水样, 每层收集 $2.5 \mathrm{~L}$ 水样, 立即加人鲁哥试剂 固定. 固定样品经过 $48 \mathrm{~h}$ 的静置沉淀后, 采用虹吸法去除上清液并浓缩至 $30 \mathrm{~mL}$. 浮游植物细胞采用 Sedgewick Rafter 计数板在 400 倍的倒置显微镜下进行计数, 所有的物种都尽可能鉴定到种属的水平 ${ }^{[24]}$, 每 个样品至少计数 500 个个体 ${ }^{[25]}$, 同时对每一个物种的尺寸大小进行测量. 浮游植物体积的估算基于标准的 几何学公式 ${ }^{[26]}$,并按照密度为 $1 \mathrm{~g} / \mathrm{cm}^{3}$ 进行估算. 2014 年 10 月 24 日,水库表层蓝藻水华优势种为铜绿微囊 藻 (Microcystis aeruginosa) , 经过估算生物量为 $14.29 \mathrm{mg} / \mathrm{L}$, 占浮游植物生物量的 $82.65 \%{ }^{[19]}$.

\section{7 后生浮游动物}

后生浮游动物定性样品用 $25^{\#}$ 浮游生物网于水体底层垂直向上拖网至表层, 样品带回实验室用纯水清 养 4 12 h, 在体视显微镜下对桡足类镖水蚤 (舌状叶镖水蚤) 进行挑选、富集, 碳、氮稳定同位素样品和生态 化学计量 P 样品各收集 3 份. 所有样品均置于 $50^{\circ} \mathrm{C}$ 烘箱中烘干 $48 \mathrm{~h}$ 至恒重, 碳稳定同位素样品用 $12 \mathrm{~mol} / \mathrm{L}$ 浓盐酸在干燥器熏蒸 $4 \mathrm{~h}$ 处理后, 在 $50^{\circ} \mathrm{C}$ 烘箱再次干燥 $4 \mathrm{~h}$. 所有样品均保存在真空干燥器中 ${ }^{[23]}$.

定量样品用 $5 \mathrm{~L}$ 采水器采集表层、氧跃层和底层水样, 每层采 $20 \mathrm{~L}$ 水样, 现场用 $25^{\#}$ 浮游生物网过滤至 采样瓶中, 加人波恩试液固定. 对固定好的样品进行定容, 用移液枪吸取 $1 \mathrm{~mL}$ 样品至 $1 \mathrm{~mL}$ 计数框中. 在倒 置显微镜或解剖境下观察样品, 进行种类鉴定并计数; 通常每份样品至少鉴定 300 个个体. 浮游动物丰度的 计算参考章宗涉和黄祥飞的方法 ${ }^{[27]}$, 采用体积法, 将每个浮游动物当成一个几何图形, 按求积公式获得生物 体积, 并假定浮游动物的密度为 $1 \mathrm{~g} / \mathrm{cm}^{3}$, 计算浮游动物的生物量. 求积公式参考文献 [ 27], 测量相应种类的 长、宽和高的数据, 代人公式得到湿重生物量.

\section{8 碳、氮稳定同位素测定}

利用稳定同位素质谱仪 (美国 Thermo Fisher Scientific Inc.) 测定悬浮物和浮游动物的碳、氮稳定同位 素 ${ }^{[23]}$. 浮游动物磷含量采用国家标准钿锑抗分光光度法进行检测 ${ }^{[23,28]}$.

\section{9 营养级计算}

利用浮游动物与悬浮物之间的 $\delta^{15} \mathrm{~N}$ 值差异来计算浮游动物的营养级水平, $\delta^{15} \mathrm{~N}$ 的营养级分馏系数取 $3.4 \%{ }^{[29]}$. 


\subsection{0 数据分析}

所有的统计分析使用 R(version 4.1.0) ( R Development Core Team,2021) ${ }^{[30]}$ 和 PRIMER 7.0 进行分析. 分 析群落数据前将浮游动物生物量进行 Hellinger 转化, 除 $\mathrm{pH}$ 值以外的所有环境因子进行对数转化. 利用相似 性分析 (analysis of similarity, ANOSIM) 评价不同组之间浮游动物群落是否存在显著差异. 通过 $\mathrm{R}$ 软件中 vegan 包进行 Mantel 检验、几余分析 (redundancy analysis, RDA) 和方差分解分析 (variation partitioning analysis, VPA), 利用 plspm 包进行偏最小二乘法路径模型 (PLS-PM) 分析, 利用 ggplot2 包进行绘图. 采用 Mantel 分析选择能够显著解释浮游动物群落组成显著变化的环境因子 $(P<0.05)$. 采用 RDA 分析进一步检 验 Mantel 分析篎选的环境因子对浮游动物群落的解释量, 解释量使用校正后的 $R^{2}$. 使用 VPA 分析来量化食 物质量 (水体 $\mathrm{C}: \mathrm{P}$ 比值和 $\mathrm{N}: \mathrm{P}$ 比值) 和食物浓度 (自由生浮游细菌丰度、绿藻生物量和蓝藻生物量) 对浮游 动物群落组成的贡献. 最后使用路径模型分析考察食物质量和食物浓度对浮游动物群落的直接和间接效应.

\section{2 结果}

\section{1 浮游动物群落结构的基本特征}

共鉴定后生浮游动物 23 种,其中桡足类 5 种、枝角类 9 种、轮虫 9 种 (表 1). 研究期间,浮游动物总丰度 的变化范围为 $3.70 \sim 216.30 \mathrm{ind}$. / L , 平均丰度为 $66.92 \mathrm{ind} . / \mathrm{L}$. 其中桡足类、枝角类和轮虫分别占总丰度比例 的 49.4\%、29.6\% 和 $21.0 \%$ (图 1a). 浮游动物总生物量的变化范围为 $21.63 \sim 1994.54 \mu \mathrm{g} / \mathrm{L}$, 平均生物量为 $392.81 \mu \mathrm{g} / \mathrm{L}$ (图 $1 \mathrm{~b})$. 其中桡足类生物量占比最大 $(73.5 \%)$, 枝角类和轮虫生物量分别占总生物量的 $23.1 \%$ 和 $3.4 \%$.

表 1 溪东水库后生浮游动物种类

Tab.1 The species of metazooplankton in Xidong Reservoir

\begin{tabular}{|c|c|c|c|c|c|}
\hline & 种类 & 拉丁学名 & & 种类 & 拉丁学名 \\
\hline \multirow[t]{5}{*}{ 桡足类 } & 剑水蚤 & Cyclops sp. & 枝角类 & 多刺裸腹溞 & Moina macrocopa \\
\hline & 温中剑水蚤 & Mesocyclops thermocyclopoides & & 微型裸腹溞 & Moina micrura \\
\hline & 舌状叶镖水虫 & Phyllodiaptomus tunguidus & 轮虫 & 前节晶囊轮虫 & Asplanchna priodonta \\
\hline & 台湾温剑水蚤 & Thermocyclops taihokuensis & & 螺形龟甲轮虫 & Keratella cochlearis \\
\hline & 微小近剑水蚤 & Tropocyclops parvus & & 曲腿龟甲轮虫 & Keratella valga \\
\hline \multirow[t]{7}{*}{ 枝角类 } & 长额象鼻溞 & Bosmina longirostris & & 福建叶轮虫 & Notholca fujianensis \\
\hline & 颈沟基合溞 & Bosminopsis deitersi & & 截头皱甲轮虫 & Ploesoma truncatum \\
\hline & 角突网纹溞 & Ceriodaphnia cornuta & & 多肢轮虫 & Polyarthra sp. \\
\hline & 方形网纹溞 & Ceriodaphnia quadrangula & & 刺盖异尾轮虫 & Trichocerca capucina \\
\hline & 圆形盘肠溞 & Chydorus sphaericus & & 圆筒异尾轮虫 & Trichocerca cylindrica \\
\hline & 短尾秀体溞 & Diaphanosoma brachyurum & & 对棘异尾轮虫 & Trichocerca similis \\
\hline & 长肢秀体溞 & Diaphanosoma leuchtenbergianum & & & \\
\hline
\end{tabular}

\section{2 浮游动物群落结构的时空差异}

ANOSIM 检验表明,后生浮游动物群落组成在不同时期之间的差异显著 ( Global $r=0.452, P=0.001)$,在 不同水深之间的差异不显著 (表 2). 在不同时期之间, 桡足类群落在非水华期 1 与非水华期 2( Global $r=$ $0.237, P=0.019)$ 之间差异显著, 但在水华期与非水华期 1 、水华期与非水华期 2 之间的差异均不显著 $(P>$ $0.05)$. 枝角类和轮虫群落在水华期、非水华期 1 和非水华期 2 之间的差异均显著 $(P<0.05)$.

\section{3 环境因子与浮游动物群落的关系}

Mantel 检验表明,后生浮游动物群落与浊度、总碳、总氮、水体 $\mathrm{N}: \mathrm{P}$ 比值、轮虫生物量和桡足类生物量显 著相关. 从浮游生物各类群来看, 与桡足类群落显著相关的因子包括浊度、总碳、水体 $\mathrm{N}: \mathrm{P}$ 比值和轮虫生物 量; 与枝角类群落显著相关的因子包括水温、总碳、总有机碳、蓝藻 Chl. $a$ 、浮游植物 Chl. $a$ 、蓝藻生物量和浮游 植物总生物量; 与轮虫群落显著相关的因子包括总碳、绿藻 Chl. $a$ 和绿藻生物量 $($ 表 3,4$)$. 


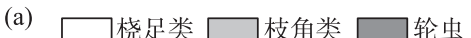

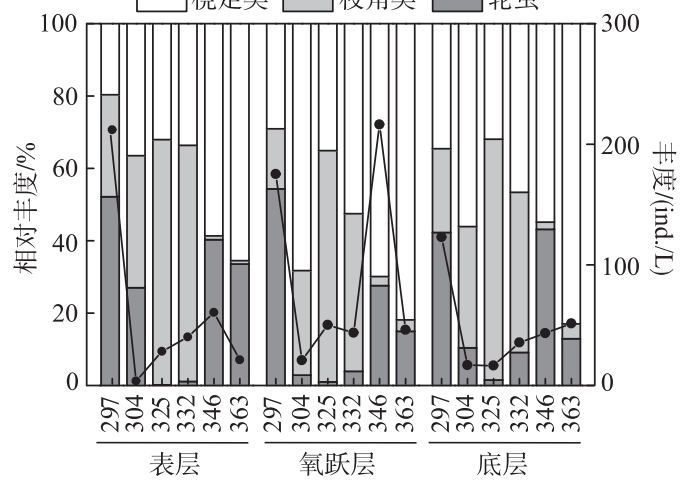

(b)

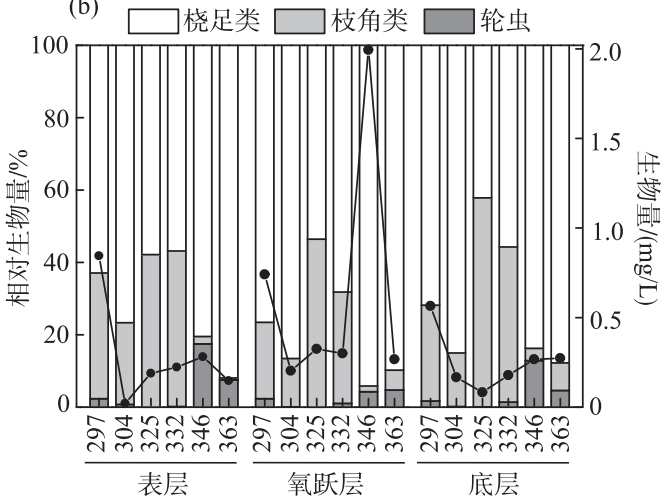

图 1 后生浮游动物的丰度和生物量组成变化

Fig.1 Spatiotemporal dynamics of metazooplankton community based on abundance (a) and biomass (b)

表 2 基于生物量的不同时空尺度后生浮游动物群落的 ANOSIM 检验*

Tab.2 Analysis of similarity (ANOSIM) statistics testing differences of metazooplankton biomass-based community across space and time

\begin{tabular}{|c|c|c|c|c|c|c|c|c|}
\hline \multirow{2}{*}{ 分组 } & \multicolumn{2}{|c|}{ 后生浮游动物 } & \multicolumn{2}{|c|}{ 桡足类 } & \multicolumn{2}{|c|}{ 枝角类 } & \multicolumn{2}{|c|}{ 轮虫 } \\
\hline & $r$ & $P$ & $r$ & $P$ & $r$ & $P$ & $r$ & $P$ \\
\hline 水华期、非水华期 1 、非水华期 2 & 0.452 & 0.001 & 0.128 & 0.053 & 0.554 & 0.001 & 0.590 & 0.001 \\
\hline 水华期、非水华期 1 & 0.339 & 0.009 & 0.169 & 0.093 & 0.428 & 0.006 & 0.271 & 0.026 \\
\hline 水华期、非水华期 2 & 0.378 & 0.004 & -0.002 & 0.413 & 0.598 & 0.002 & 0.983 & 0.002 \\
\hline 非水华期 1 、非水华期 2 & 0.724 & 0.002 & 0.237 & 0.019 & 0.689 & 0.002 & 0.502 & 0.002 \\
\hline 表层、氧跃层、底层 & -0.083 & 0.892 & -0.089 & 0.911 & -0.045 & 0.672 & -0.134 & 0.995 \\
\hline 表层、氧跃层 & -0.028 & 0.606 & -0.035 & 0.574 & 0.007 & 0.368 & -0.111 & 0.905 \\
\hline 表层、底层 & -0.124 & 0.916 & -0.174 & 0.996 & -0.015 & 0.483 & -0.131 & 0.952 \\
\hline 氧跃层、底层 & -0.089 & 0.784 & -0.054 & 0.684 & -0.167 & 0.948 & -0.165 & 0.950 \\
\hline
\end{tabular}

* 加粗表示显著差异 $(P<0.05)$.

$\mathrm{RDA}$ 结果表明, 食物质量 (水体 $\mathrm{C}: \mathrm{P}$ 和 $\mathrm{N}: \mathrm{P}$ 比值) 和食物浓度 (自由生浮游细菌、绿藻生物量和蓝藻生 物量) 对后生浮游动物群落 RDA 轴 1 和轴 2 的总解释量为 $34.6 \%$ (图 2a); 方差分解结果表明,食物质量和 食物浓度对后生浮游动物群落的解释度为 $33 \%$, 食物质量和食物浓度对浮游动物群落的影响极显著 $(P<$ $0.01)$. 从浮游生物各类群来看, 食物质量和食物浓度对桡足类的解释量为 $32 \%$, 桡足类群落受食物质量影 响更大 $(P<0.01)$, 但是食物浓度对桡足类群落的解释不显著 $(P>0.05)$. 食物质量和食物浓度对枝角类的解 释量为 $29 \%$, 枝角类群落主要受食物浓度的显著影响 $(P<0.01)$, 食物质量对枝角类群落的解释不显著 $(P>$ $0.05)$. 食物质量和食物浓度对轮虫的解释量为 $40 \%$, 食物质量和食物浓度均显著影响轮虫群落 $(P<0.05)$, 食物质量的影响大于食物浓度 (图 $2 \mathrm{~b}$ ). 路径分析表明, 水温对食物质量和食物浓度有着显著的直接效应 $(P=0.045, P=0.011)$, 路径系数分别为 0.48 和 0.62 ; 食物浓度对枝角类有显著的直接效应 $(P=0.018)$, 路径 系数为 0.68 ,轮虫对桡足类有显著的直接效应 $(P<0.01)$, 路径系数为 0.85 (图 $2 \mathrm{c}$ ).

\section{4 营养级对镖水蚤的影响}

碳稳定同位素分析结果表明,水华期舌状叶镖水蚤的主要食物来源是水库水体中的悬浮物 (图 3a). 水 华期至非水华期 2 , 舌状叶镖水蚤与悬浮物之间的营养级变化范围为 $1.28 \sim 2.84$. 从营养级与磷含量和水温 的分析来看 (图 $3 \mathrm{~b})$, 舌状叶镖水蚤的营养级随着体内磷含量 $\left(\mathrm{P}_{\mathrm{Zoo}}\right)$ 降低而增加 $(n=5, r=-0.79, P=$ $0.069)$; 随着表层水温的下降, 舌状叶镖水蚤的营养级显著增加 $(n=5, r=-0.84, P=0.049)$. 从磷含量与水 
表 3 后生浮游动物群落与环境因子的 Mantel 检验结果 *

Tab.3 Spearman's correlations of metazooplankton community with environmental factors based on Mantel tests

\begin{tabular}{|c|c|c|c|c|c|c|c|c|}
\hline \multirow{2}{*}{ 环境因子 } & \multicolumn{2}{|c|}{ 后生浮游动物 } & \multicolumn{2}{|c|}{ 桡足类 } & \multicolumn{2}{|c|}{ 枝角类 } & \multicolumn{2}{|c|}{ 轮虫 } \\
\hline & $r$ & $P$ & $r$ & $P$ & $r$ & $P$ & $r$ & $P$ \\
\hline 水温 & 0.133 & 0.092 & 0.073 & 0.204 & 0.177 & 0.038 & 0.127 & 0.093 \\
\hline $\mathrm{pH}$ & 0.149 & 0.090 & 0.091 & 0.193 & 0.197 & 0.054 & 0.183 & 0.056 \\
\hline 溶解氧 & -0.032 & 0.615 & -0.067 & 0.825 & 0.075 & 0.155 & -0.032 & 0.601 \\
\hline 浊度 & 0.470 & 0.007 & 0.405 & 0.007 & 0.104 & 0.217 & -0.073 & 0.665 \\
\hline 电导率 & -0.132 & 0.798 & -0.084 & 0.669 & -0.173 & 0.933 & -0.121 & 0.842 \\
\hline 氧化还原电位 & -0.060 & 0.698 & -0.060 & 0.723 & -0.074 & 0.788 & 0.090 & 0.170 \\
\hline 总碳 & 0.232 & 0.024 & 0.188 & 0.039 & 0.254 & 0.011 & 0.309 & 0.005 \\
\hline 总有机碳 & 0.247 & 0.059 & 0.177 & 0.125 & 0.290 & 0.024 & 0.185 & 0.095 \\
\hline 总氮 & 0.323 & 0.037 & 0.083 & 0.240 & -0.123 & 0.885 & -0.101 & 0.814 \\
\hline $\mathrm{NO}_{2}^{-}-\mathrm{N}$ & 0.132 & 0.075 & 0.029 & 0.356 & -0.048 & 0.658 & 0.132 & 0.093 \\
\hline $\mathrm{NO}_{3}^{-}-\mathrm{N}$ & 0.023 & 0.338 & -0.110 & 0.770 & -0.045 & 0.601 & 0.023 & 0.346 \\
\hline $\mathrm{NH}_{3}-\mathrm{N}$ & -0.024 & 0.514 & -0.001 & 0.470 & -0.102 & 0.810 & -0.024 & 0.536 \\
\hline 总磷 & -0.022 & 0.487 & 0.070 & 0.285 & -0.109 & 0.818 & -0.022 & 0.521 \\
\hline $\mathrm{PO}_{4}^{3-}-\mathrm{P}$ & -0.099 & 0.785 & 0.045 & 0.349 & -0.168 & 0.923 & -0.099 & 0.791 \\
\hline $\mathrm{C}: \mathrm{N}$ & 0.190 & 0.065 & 0.150 & 0.104 & 0.187 & 0.072 & 0.111 & 0.162 \\
\hline$C: P$ & 0.097 & 0.202 & 0.105 & 0.168 & 0.043 & 0.344 & -0.001 & 0.469 \\
\hline $\mathrm{N}: \mathrm{P}$ & 0.178 & 0.033 & 0.192 & 0.028 & 0.033 & 0.336 & 0.142 & 0.063 \\
\hline 蓝藻 Chl. $a$ & 0.258 & 0.062 & 0.204 & 0.095 & 0.265 & 0.038 & 0.209 & 0.084 \\
\hline 绿藻 Chl. $a$ & 0.004 & 0.418 & 0.015 & 0.403 & -0.020 & 0.510 & 0.369 & 0.003 \\
\hline 杂色藻 Chl. $a$ & 0.152 & 0.150 & 0.106 & 0.225 & 0.186 & 0.092 & 0.154 & 0.120 \\
\hline 总 Chl. $a$ & 0.242 & 0.056 & 0.181 & 0.138 & 0.282 & $\mathbf{0 . 0 3 3}$ & 0.172 & 0.127 \\
\hline
\end{tabular}

* 加粗表示显著相关 $(P<0.05)$.

表 4 后生浮游动物群落与浮游生物生物量的 Mantel 检验结果 *

Tab.4 Spearman's correlations of the metazooplankton community with food concentration based on Mantel tests

\begin{tabular}{|c|c|c|c|c|c|c|c|c|}
\hline \multirow{2}{*}{ 浮游生物 } & \multicolumn{2}{|c|}{ 后生浮游动物 } & \multicolumn{2}{|c|}{ 桡足类 } & \multicolumn{2}{|c|}{ 枝角类 } & \multicolumn{2}{|c|}{ 轮虫 } \\
\hline & $r$ & $P$ & $r$ & $P$ & $r$ & $P$ & $r$ & $P$ \\
\hline 浮游细菌 & -0.076 & 0.657 & -0.146 & 0.890 & 0.176 & 0.084 & 0.005 & 0.428 \\
\hline 蓝藻生物量 & 0.185 & 0.110 & 0.141 & 0.170 & 0.258 & 0.045 & 0.208 & 0.089 \\
\hline 绿藻生物量 & 0.010 & 0.448 & -0.012 & 0.530 & 0.131 & 0.051 & 0.187 & 0.029 \\
\hline 硅藻生物量 & -0.058 & 0.663 & -0.083 & 0.717 & 0.082 & 0.192 & 0.188 & 0.076 \\
\hline 裸藻生物量 & -0.046 & 0.532 & -0.067 & 0.581 & 0.108 & 0.248 & 0.067 & 0.259 \\
\hline 甲藻生物量 & -0.030 & 0.374 & -0.024 & 0.418 & 0.030 & 0.371 & 0.024 & 0.326 \\
\hline 隐藻生物量 & -0.082 & 0.739 & -0.107 & 0.808 & 0.041 & 0.299 & 0.164 & 0.088 \\
\hline 金藻生物量 & 0.058 & 0.303 & 0.088 & 0.227 & -0.043 & 0.618 & -0.137 & 0.912 \\
\hline 浮游植物总生物量 & 0.196 & 0.127 & 0.151 & 0.168 & 0.262 & 0.042 & 0.212 & 0.077 \\
\hline 轮虫生物量 & 0.390 & 0.011 & 0.336 & 0.023 & 0.251 & 0.065 & 0.274 & 0.048 \\
\hline 枝角类生物量 & 0.228 & 0.068 & 0.094 & 0.247 & 0.520 & 0.002 & 0.125 & 0.125 \\
\hline 桡足类生物量 & 0.642 & 0.001 & 0.664 & 0.001 & 0.191 & 0.103 & 0.238 & 0.070 \\
\hline
\end{tabular}

*加粗表示显著相关 $(P<0.05)$.

体总磷浓度和水温的分析来看, 舌状叶镖水蚤体内的磷含量与水柱总磷平均浓度 $\left(\mathrm{TP}_{\text {Average }}\right)$ 呈显著正相关 $(n=5, r=0.93, P=0.015)$, 与水温呈现极显著正相关 $(n=5, r=0.95, P=0.007)$. 


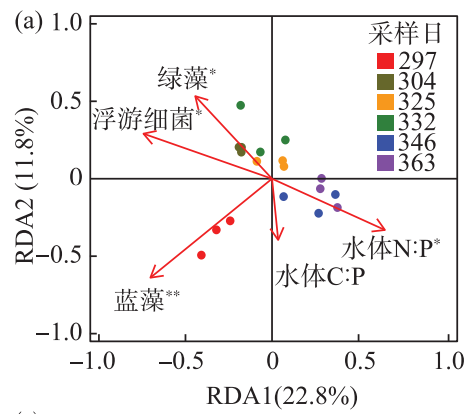

(b)
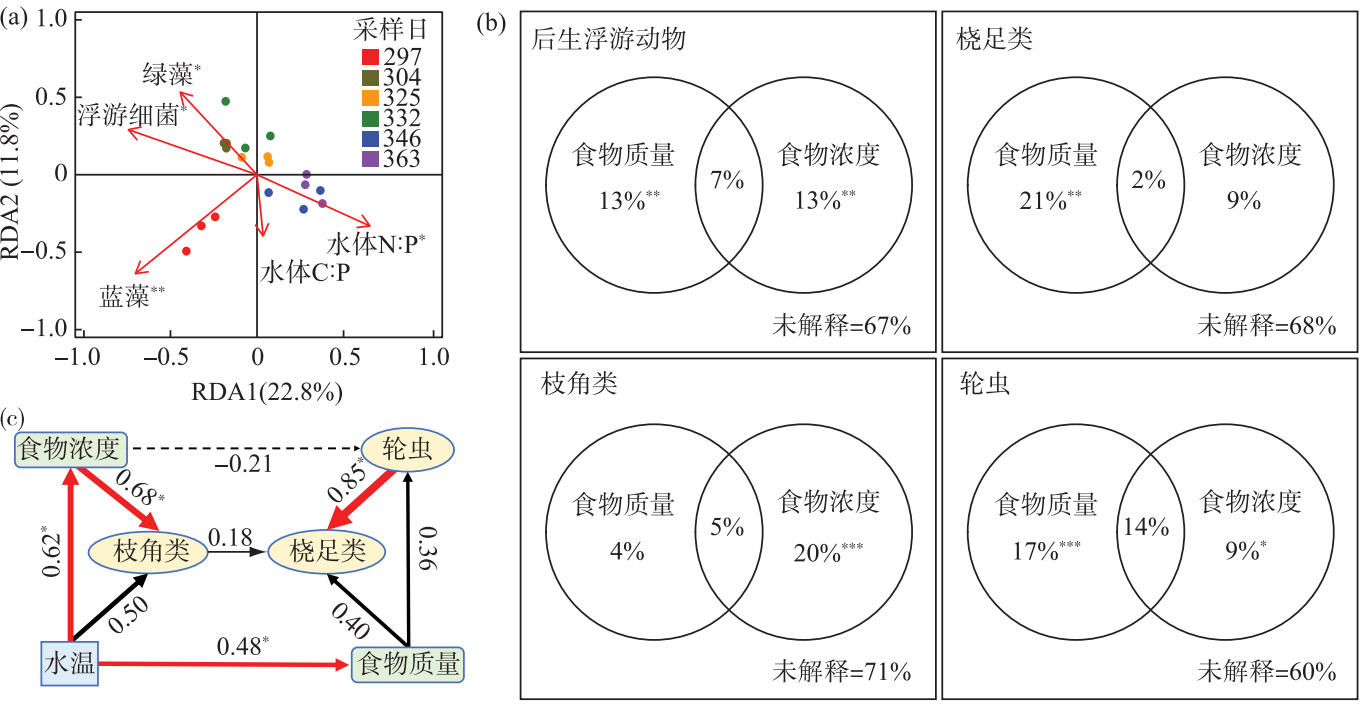

图 2 食物质量和浓度与后生浮游动物群落的关系:RDA 分析 (a)、VPA 分析 (b)、PLS-PM 分析 (c)

$$
(* * * P<0.001, * * P<0.01, * P<0.05)
$$

Fig.2 Relationship between food quality or concentration and metazooplankton community: redundancy analysis $(a)$, variance partitioning analysis $(b)$, and partial least squares path modeling analysis (c)

$$
(* * * P<0.001, * * P<0.01, * P<0.05)
$$
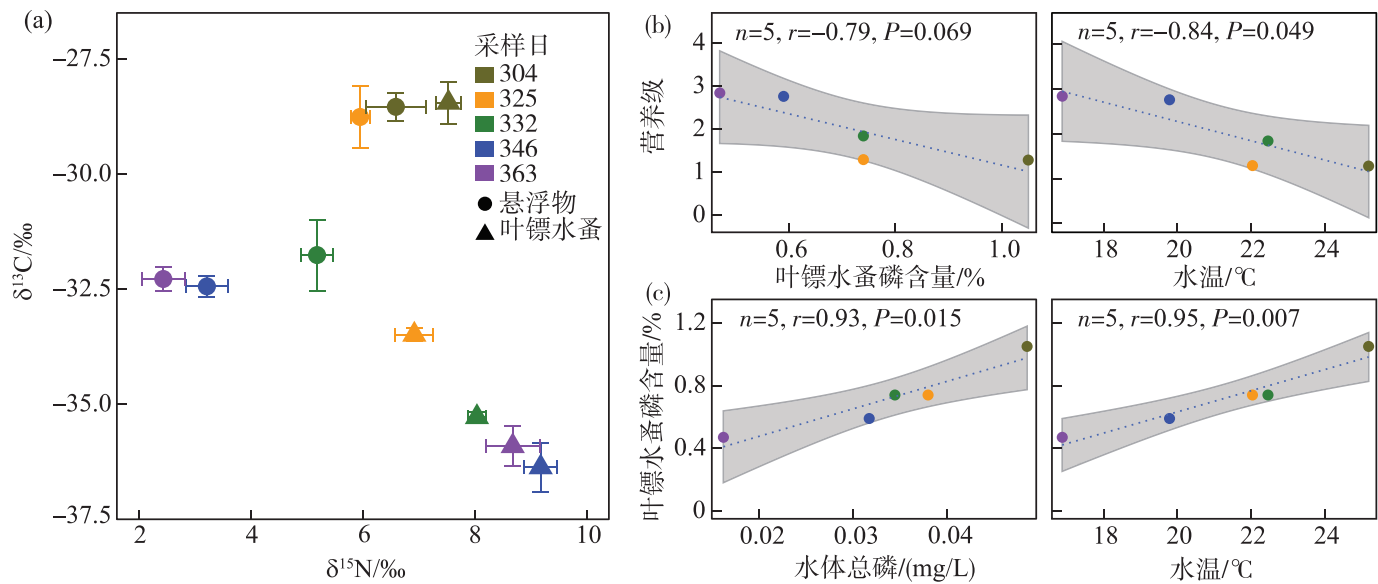

图 3 舌状叶镖水蚤与悬浮物碳氮稳定同位素分布特征 (a)、舌状叶镖水蚤营养级与磷含量和 水温的关系 (b)、舌状叶镖水虫磷含量与水体总磷和水温的关系 (c)

Fig.3 Carbon and nitrogen stable isotope of Phyllodiaptomus tunguidus and suspended matter (a), relationship between trophic level and phosphorus content in P. tunguidus or water temperature (b), relationship between phosphorus content in $P$. tunguidus and total phosphorus 


\section{3 讨论}

\section{1 浮游动物群落结构与食物的关系}

温度和食物是影响浮游动物群落变化的主要因素 ${ }^{[5]}$. 轮虫个体较小、生命周期短, 通常对水体营养级的 响应相对枝角类和桡足类更敏感 ${ }^{[31-32]}$. 本研究中, 溪东水库轮虫的群落结构受环境因子的影响显著, 群落结 构在水华期、非水华期 1 和非水华期 2 之间的差异均显著, 表现出与水体总碳和绿藻生物量呈显著正相关关 系 $(P<0.05)$.

溪东水库枝角类的群落结构也受环境因子的显著影响, 蓝藻水华期枝角类主要以小型种类 (长额象鼻 泽) 为优势种, 长额象鼻溞生物量与水温、水体 $\mathrm{C}: \mathrm{N}$ 比值、自由生浮游细菌和蓝藻生物量呈显著正相关, 说明 溪东水库长额象鼻溞受水温和食物的影响, 且食物对其影响更显著. 相对浮游植物而言, 浮游细菌磷含量较 高且相对稳定, 因此细菌的食物质量较高 ${ }^{[33-34]}$. 溪东水库水体中浮游细菌与总碳和蓝藻生物量呈显著正相 关关系, 蓝藻水华为浮游细菌提供了大量碳源, 是水华期间浮游细菌大量生长的主要原因, 自由生浮游细菌 的大量生长为食菌者提供了充足的食物,进而促进小型枝角类长额象鼻溞的生长.

桡足类群落结构在水华期与非水华期之间的差异不显著, 但其群落变化与浊度、总碳、轮虫生物量和水 体 N:P 比值等因子显著相关. 桡足类生物量在非水华期 2 的中层出现急剧增加, 期间优势种舌状叶镖水蚤 的营养级均值为 2.8 . 非水华期 1 舌状叶镖水蚤的营养级均值为 1.6 , 说明舌状叶镖水蚤在非水华期 2 摄食 了更高营养水平的食物. 不过, 本研究只采用一个站位 3 个水层不同时期桡足类优势种和悬浮物数据, 并不 能完全代表整个水库生态系统的食物网. 因此, 非水华期 2 桡足类生物量剧增的原因还需要进一步深人研 究分析,包括不同站位的其他浮游动物、不同粒径悬浮物等.

\section{2 浮游动物与营养级的关系}

Boersma 等研究发现海洋桡足类浮游动物长角宽水蚤 (Temora longicornis) 的营养级随着水温升高而降 低, 主要原因是高温时它偏向摄食自养生物红胞藻 (Rhodomonas salina $)^{[13]}$; 在高温条件下, 浮游动物具更高 的新陈代谢速率, 需要更多的碳源来维持代谢需求 ${ }^{[12]}$. 同样, 本研究中, 舌状叶镖水蚤不仅是初级消费者, 也是次级消费者, 营养级变化较大, 随着水温降低而升高, 而且与体内磷浓度呈显著负相关. Boersma 等认为 长角宽水蚤在高温偏好摄食碳含量高的自养生物, 而不是低温造成氮、磷需求的增加, 但作者在实验过程中 并未检测长角宽水蚤体内磷含量的变化 ${ }^{[13]}$. 溪东水库蓝藻水华发生时期浮游动物体内的磷含量也较高, 这 与水柱总磷浓度较高相吻合. 10-12 月由于水温的下降, 水库氧跃层伴随温跃层逐渐向下移动, 最终由分层 期转变到混合期, 水柱总磷浓度逐渐降低, 导致舌状叶镖水蚤体内的磷含量下降. 在水库水体水柱的总磷浓 度下降过程中, 桡足类的生物量呈现增加趋势, 可能原因是溶解氧充足、温度适宜的湖上层区域扩大导致适 合桡足类生长繁殖的空间扩大. 因此, 水体环境总磷浓度下降与桡足类的繁殖与生长过程可能是导致桡足 类磷含量下降的主要原因. 此外, 由于营养 (磷元素) 的需求, 舌状叶镖水蚤需要摄食磷含量较高的食物, 导 致其营养级水平增加 ${ }^{[35]}$. 因此, 我们认为水温的下降伴随浮游动物营养级的增加, 不仅是因为新陈代谢的 变化, 而且是水环境总磷浓度下降与浮游动物繁殖和生长的共同作用下, 促进浮游动物偏好摄食磷含量高 的浮游生物或有机颗粒物, 导致其营养级的增加.

\section{4 参考文献}

[ 1 ] Cai QH, Sun ZY. Water environment and aquatic ecosystem of Three Gorges Reservoir, China: Progress and prospects. J Lake Sci, 2012, 24(2) : 169-177. DOI: 10.18307/2012.0201. [蔡庆华, 孙志禹. 三峡水库水环境与水生态研究的进 展与展望. 湖泊科学, $2012, \mathbf{2 4}(2): 169-177$. ]

[ 2 ] Han BP. Reservoir ecology and limnology in China: A retrospective comment. J Lake Sci, 2010, 22(2) : 151-160. DOI: 0.18307/2010.0201. [韩博平. 中国水库生态学研究的回顾与展望. 湖泊科学, 2010, 22(2): 151-160.]

[ 3 ] Yang J, Yu XQ, Liu LM et al. Algae community and trophic state of subtropical reservoirs in southeast Fujian, China. Environmental Science and Pollution Research, 2012, 19(5) : 1432-1442. DOI: 10.1007/s11356-011-0683-1.

[ 4 ] Chen BH, Liu ZW. Effect of filter-feeding omnivorous fish on zooplankton community. Ecological Science, 2012, 31(2): 161-166. [陈炳辉, 刘正文. 滤食杂食性鱼类放养对浮游动物群落结构的影响. 生态科学, 2012, 31 (2): 
161-166.]

[ 5 ] Xi LH, Li HM, Lin QQ et al. Structure and seasonality variations of zooplankton community in the pelagic zone of tropical Dashahe Reservoir, Guangdong, South China. J Lake Sci, 2015, 27 (6) : 1049-1058. DOI: 10.18307/2015.0609. [习丽 红, 李慧明, 林秋奇等. 热带富营养水库敞水区浮游动物群落结构与季节变化: 以广东大沙河水库为例. 湖泊科 学, 2015, 27(6): 1049-1058.]

[ 6 ] Sommer U, Adrian R, de Senerpont Domis L et al. Beyond the plankton ecology group (PEG) model: Mechanisms driving plankton succession. Annual Review of Ecology, Evolution, and Systematics, 2012, 43(1) : 429-448. DOI: 10.1146/annurev-ecolsys-110411-160251.

[ 7 ] Yang YF, Huang XF. Advances in ecological studies on zooplankton. J Lake Sci, 2000, 12(1) : 81-89. DOI: 10.18307/ 2000.0113. [杨宇峰, 黄祥飞. 浮游动物生态学研究进展. 湖泊科学, 2000, 12(1): 81-89.]

[ 8 ] Laspoumaderes C, Modenutti B, Elser JJ et al. Does the stoichiometric carbon: Phosphorus knife edge apply for predaceous copepods?. Oecologia, 2015, 178(2) : 557-569. DOI: 10.1007/s00442-014-3155-8.

[ 9 ] Ho PC, Okuda N, Miki T et al. Summer profundal hypoxia determines the coupling of methanotrophic production and the pelagic food web in a subtropical reservoir. Freshwater Biology, 2016, 61(10) : 1694-1706. DOI: 10.1111/fwb.12809.

[10] Zhang H, Cai M, Chen FZ. Effects of Scenedesmus obliquus with different C/P ratios on the growth and reproduction of Daphnia similis. J Lake Sci, 2017, 29(5) : 1188-1194. DOI: 10.18307/2017.0516. [张慧, 蔡敏, 陈非洲. 不同碳磷 比的斜生栅藻 (Scenedesmus obliquus) 对同型溞 (Daphnia similis) 生长和繁殖的影响. 湖泊科学, 2017, 29(5): 1188-1194. ]

[11] Burian A, Kainz MJ, Schagerl M et al. Species-specific separation of lake plankton reveals divergent food assimilation patterns in rotifers. Freshwater Biology, 2014, 59(6) : 1257-1265. DOI: 10.1111/fwb.12345.

[12] Meunier CL, Boersma M, Wiltshire KH et al. Zooplankton eat what they need: Copepod selective feeding and potential consequences for marine systems. Oikos, 2016, 125(1) : 50-58. DOI: 10.1111/oik.02072.

[13] Boersma M, Mathew KA, Niehoff B et al. Temperature driven changes in the diet preference of omnivorous copepods: No more meat when it's hot?. Ecology Letters, 2016, 19(1): 45-53. DOI: 10.1111/ele.12541.

[14] Yang J, Lv H, Yang J et al. Decline in water level boosts cyanobacteria dominance in subtropical reservoirs. Science of the Total Environment, 2016, 557/558: 445-452. DOI: 10.1016/j.scitotenv.2016.03.094.

[15] Yang JR, Lv H, Isabwe A et al. Disturbance-induced phytoplankton regime shifts and recovery of cyanobacteria dominance in two subtropical reservoirs. Water Research, 2017, 120: 52-63. DOI: 10.1016/j.watres.2017.04.062.

[16] Wang WX, Chen FZ, Gu XH. Community structures of zooplankton and its relation to environmental factors in five medium reservoirs in Nanjing City. J Lake Sci, 2017, 29(1) : 216-223. DOI: 10.18307/2017.0123. [王文侠, 陈非洲, 谷孝鸿. 南京市 5 座中型水库浮游动物群落结构及其与环境因子的关系. 湖泊科学, 2017, 29(1): 216-223.]

[17] Xue YY, Yu Z, Chen HH et al. Cyanobacterial bloom significantly boosts hypolimnelic anammox bacterial abundance in a subtropical stratified reservoir. FEMS Microbiology Ecology, 2017, 93(10): fix118. DOI: 10.1093/femsec/fix118.

[18] Guo YY, Liu M, Liu LM et al. The antibiotic resistome of free-living and particle-attached bacteria under a reservoir cyanobacterial bloom. Environment International, 2018, 117: 107-115. DOI: 10.1016/j.envint.2018.04.045.

[19] Xue YY, Chen HH, Yang JR et al. Distinct patterns and processes of abundant and rare eukaryotic plankton communities following a reservoir cyanobacterial bloom. The ISME Journal, 2018, 12(9) : 2263-2277. DOI: 10.1038/s41396-0180159-0.

[20] Zhu ZX, Yang J. The spatial distribution of reservoirs in Fujian Province: Higher density but lower storage in coastal than inland regions. J Lake Sci, 2018, 30(2) : 567-580. DOI: 10.18307/2018.0227. [ 朱珍香, 杨军. 福建水库空间分布特 征: 沿海密度高水量少、内陆密度低水量多. 湖泊科学, 2018, 30(2) : 567-580.]

[21] Liu M, Liu LM, Chen HH et al. Community dynamics of free-living and particle-attached bacteria following a reservoir $\mathrm{Mi}$ crocystis bloom. Science of the Total Environment, 2019, 660: 501-511. DOI: 10.1016/j.scitotenv.2018.12.414.

[22] Liu L, Yang J, Yu X et al. Patterns in the composition of microbial communities from a subtropical river: Effects of environmental, spatial and temporal factors. PLoS One, 2013, 8(11) : e81232. DOI: 10.1371/journal.pone.0081232.

[23] Gao XF, Chen HH, Gu BH et al. Particulate organic matter as causative factor to eutrophication of subtropical deep freshwater: Role of typhoon (tropical cyclone) in the nutrient cycling. Water Research, 2021, 188: 116470. DOI: 10.1016/j. watres.2020.116470. 
[24] Hu HJ, Wei YX eds. The freshwater algae of China-systematics, taxonomy and ecology. Beijing: Science Press, 2006. [ 胡 鸿钧, 魏印心. 中国淡水藻类——系统、分类及生态. 北京: 科学出版社, 2006.]

[25] Lv H, Yang J, Liu LM et al. Temperature and nutrients are significant drivers of seasonal shift in phytoplankton community from a drinking water reservoir, subtropical China. Environmental Science and Pollution Research, 2014, 21(9) : 5917 5928. DOI: $10.1007 / \mathrm{s} 11356-014-2534-3$.

[26] Hillebrand H, Dürselen CD, Kirschtel D et al. Biovolume calculation for pelagic and benthic microalgae. Journal of Phycology, 1999, 35(2) : 403-424. DOI: 10.1046/j.1529-8817.1999.3520403.x.

[27] Zhang ZS, Huang XF eds. Research methods of freshwater plankton. Beijing: Science Press, 1991. [章宗涉, 黄祥飞. 淡 水浮游生物研究方法. 北京: 科学出版社, 1991.]

[28] Elser JJ, Acharya K, Kyle M et al. Growth rate-stoichiometry couplings in diverse biota. Ecology Letters, 2003, 6( 10): 936-943. DOI: 10.1046/j.1461-0248.2003.00518.x.

[29] Post DM. Using stable isotopes to estimate trophic position: Models, methods, and assumptions. Ecology, 2002, 83(3) : 703-718. DOI: 10.1890/0012-9658(2002)083[0703: USITET]2.0.CO;2.

[30] R Core Team. R Foundation for Statistical Computing; Vienna, Austria: 2021. R: A language and environment for statistical computing. http://www. r-project. org, 2021.

[31] Lin QQ, Hu R, Duan SS et al. Reservoir trophic states and the response of plankton in Guangdong Province. Acta Ecologica Sinica, 2003, 23(6) : 1101-1108. [林秋奇, 胡韧, 段舜山等. 广东省大中型供水水库营养现状及浮游生物的响 应. 生态学报, 2003, 23(6): 1101-1108.]

[32] Rao LH, Wu ZY, Xu J et al. Relationship between environmental factors of the water and rotifer community structure in West Lake, Hangzhou. J Lake Sci, 2013, 25(1): 138-146. DOI: 10.18307/2013.0118. [ 饶利华, 吴芝瑛, 徐骏等. 杭 州西湖轮虫的群落结构及与水体环境因子的关系. 湖泊科学, 2013, 25(1): 138-146.]

[33] Godwin CM, Cotner JB. Aquatic heterotrophic bacteria have highly flexible phosphorus content and biomass stoichiometry. The ISME Journal, 2015, 9(10) : 2324-2327. DOI: 10.1038/ismej.2015.34.

[34] Chen MR, Zhao SY, Lin QQ et al. Cladoceran distribution in reservoirs of Guangdong Province, South China. J Lake Sci, 2007, 19(1) : 77-86. DOI: 10.18307/2007.0112. [ 陈绵润, 赵帅营, 林秋奇等. 广东省水库枝角类组成特征的初步 研究. 湖泊科学, $2007,19(1): 77-86$.

[35] Elser JJ, O'Brien WJ, Dobberfuhl DR et al. The evolution of ecosystem processes: Growth rate and elemental stoichiometry of a key herbivore in temperate and arctic habitats. Journal of Evolutionary Biology, 2000, 13(5) : 845-853. DOI: 10. 1046/j.1420-9101.2000.00215.x. 